DOI 10.22394/1818-4049-2017-78-1-171-174

УДК 351.82

\title{
О.Г. Поливаева
}

\section{Совершенствование кадрового сопровождения процедур оценки регулирующего воздействия проектов и экспертизы действующих нормативных правовых актов}

B статье рассмотрены вопросы, связанные с необходимостью развития кадрового обеспечения процедур оценки регулирующего воздействия (далее - ОРВ) проектов и экспертизы действующих нормативных правовых актов. Обращено внимание на актуальность развития экспертного сопровождения процедур ОРВ на территории Дальневосточного федерального округа и на необходимость консолидаиии усилий органов государственного и мунииипального управления, бизнессообиества, образовательных организаций по развитию кадрового обеспечения регуляторной политики. Показана роль и направления деятельности образовательных организаиий высшего образования в кадровом обеспечении проиедур ОРВ. Представлена общая характеристика направлений деятельности межрегионального иентра компетенций по вопросам ОРВ, создаваемого на базе Дальневосточного института управления - филиала РАНХиГС.

In this article the questions connected with the need of development of staffing of the assessment procedures of regulating influence of the projects and examinations of the existing regulations (ARI) are considered. The attention to the relevance of development of expert support of the ARI procedures in the territory of the Far-Eastern federal district and to the need of consolidation of efforts of the bodies of public and municipal administration, business community, educational organizations for development of the staffing of regulatory policy is paid. The role and activities of the educational organizations of higher education in staffing of the ARI procedures is shown. The general characteristic of activities of the interregional center of competences concerning ARI, created on the basis of the Far-Eastern institute of management - branch of RANEPA is presented.

Ключевые слова: оценка регулируюшего воздействия, консолидация деятельности, профессиональные компетениии, экспертное сообиество, роль образовательных организаиий высшего образования, центр компетенций.

Keywords: assessment of the regulating influence, staffing, activity consolidation, professional competences, expert community, role of the educational organizations of the higher education, center of competences.

Процедуры оценки регулирующего воздействия проектов и экспертизы действующих нормативных правовых актов (ОРВ) получили в настоящее время широкое распространение на всех уровнях государственного управцения. В рамках этих процедур проводится публичная оценка проектов и действующей нормативной правовой базы, формирующей условия дмя активизации предпринимательской деятемьности.

По мнению Президента Российского союза промышиенников и предприниматемей Александра Шохина, “... оцен-

Поциваева Оцьга Геннадьевна - канд. экон. наук, доцент, зам. директора по науке, Дальневосточный институт управления - фимиал РАНХиГС (г. Хабаровск). E-mail: polivaeva@list.ru. 
ка регумирующего воздействия явцяется одним из кАючевьх эмементов системы мер по умучшению качества правового регулирования экономических отношений" [1]. Применение процедуры ОРВ способствует сокращению комичества неэффективньг нормативньг правовых актов, обеспечению прозрачности принимаемых в рамках государственной регуляторной помитики решений, устранению избыточных требований к субъектам предприниматемьства.

Развитие механизма OPB на всех уровнях государственного и муниципального управмения, внедрение процедуры оценки фактического воздействия нормативных правовьх актов, развитие нормативной правовой базы в сфере поддержки предприниматемьства обусловиивают необходимость расширения масштабов экспертного сопровождения процедур ОРВ.

Следует отметить, что актуамьность этой задачи в Дамьневосточном федеральном округе существенно возрастает в связи с реализацией политики приоритетного и опережающего социальноэкономического развития Дальнего Востока, что сопровождается развитием нормативной правовой базы в сфере поддержки предприниматемьства и привмечения инвестиций.

Масштабность текущего и перспективного использования механизма ОРВ как инструмента диалога вмасти и бизнеса требует консомидации деятемњности органов государственного и муниципамьного управмения, бизнес-сообщества, образовательньг организаций с целью формирования адекватного кадрового обеспечения реализации эффективной регумяторной политики на Дальнем Востоке.[2]

Одной из проблем в достижении жемаемьг эффектов явияется недостаточность кадров, обцадающих профессиональными компетенциями в области реализации регуляторной помитики и оценки регумирующего воздействия, а также необходимость расширения экспертного сообщества.

Очевидно, что сама природа механизма ОРВ требует от экспертного сообщества наличия профессиональньх компе- тенций как минимум в обцасти права, экономики, менеджмента. Организации высшего образования обладают достаточным потенциалом дия активного участия в процессах кадрового обеспечения процедур ОРВ, развития профессионального экспертного сообщества и формирования профессиональных компетенций в экономико-правовой сфере.

Сцедует отметить, что участие в механизме кадрового обеспечения процедур ОРВ представмяет объективный интерес дмя образоватемьных организаций высшего образования, что обусловлено следующими обстоятельствами.

Во-первьх, как показали результаты опроса, превалирующая часть студентов имеет весьма слабое представмение о сущности, цемях и задачах ОРВ.

Во-вторьгх, это определено взаимосвязью задач образовательного процесса с функциями ОРВ (например, информационная, аналитическая, нормотворческая, проектная, профориентационная, мотивационная, обучающая, развивающая функции ОРВ) с позиций их роми дмя обучаюшихся. Содержание этих функций во многом взаимосвязано с видами профессиональной деятемьности и формированием компетенций обучающихся высшей шкомы.

В-третьих, образоватемьные организации имеют ряд преимуществ, использование которьх может способствовать развитию процедуры ОРВ:

наличие высококвалифицированных научно-педагогических кадров как peсурса экспертного сопровождения ОРВ;

методомогические и методические возможности аккумулирования информации о мучших отечественных и зарубежных практиках OPB;

возможность привлечения обучающихся к сбору и обработке информации по ОРВ, например, в рамках организации научно-исследоватемьской работы, выполнения курсовых и выпускных квамификационных работ и т.п.;

возможность стать площадкой дия пубцичных дискуссий по вопросам ОРВ, что, в свою очередь, будет способствовать развитию информационной открытости деятельности органов государственного 
управмения и повышению эффективности диалога вмасти и бизнеса.

В рамках консолидации деятельности участников ОРВ в направлении развития кадрового обеспечения предмагается использование механизма центра компетенции, т.е. центра сбора, систематизации, распространения и приумножения знаний и эффективных практик ОРВ. Предпосыцкой к созданию центров компетенций явмяется, как правимо, возникновение новых системных проблем в самых разных сопряженных областях (например, для ОРВ - вопросы экономики, финансов, права, социологии т.п.), дия решения которых необходимы междисциплинарные команды экспертов и соответствующие методомогии.

С инициативой создания такого центра компетенций межрегионального уровня дАя дальневосточных субъектов Российской Федерации на Дальневосточном форуме предпринимателей в октябре 2016 г. выступили Министерство экономического развития Хабаровского края и Дальневосточный институт управцения филиал РАНХиГС.

В качестве основных направлений деятельности центра компетенций предмагаются:

1. Содействие формированию и развитию компетенций по ОРВ у руководителей и специалистов органов государственного и муниципального управцения:

разработка и реализация программ курсов повышения квалификации по вопросам OPB;

обзор мучших практик в сфере ОРВ;

формирование регионального "банка" учебно-методического обеспечения курсов повышения квалификации;

разработка и распространение на территории ДФО унифицированнњгх типовых программ повышения квалификации в сфере ОРВ.

2. Содействие формированию и развитию компетенций по ОРВ у представитемей предпринимательского сообщества:

организация и проведение практикоориентированных семинаров, вебинаров, консультаций для представителей бизнеса;

проведение социологических исследо- ваний по оценке эффективности ОРВ; разработка и издание учебнометодических пособий, рекомендаций.

3. Содействие формированию и развитию компетенций по ОРВ у экспертного сообщества:

формирование пума экспертов из чис$\Lambda$ научно-педагогических работников образовательных организаций;

организация постоянно действующей дискуссионной площадки дия экспертов; проведение научных исследований в сфере регуляторной помитики;

проведение публичных презентаций результатов научных исследований, в том числе с использованием возможностей Информационного портаха об Оценке регумирующего воздействия;

участие научно-педагогических кадров в оценке фактического воздействия регуляторного механизма (разработка методических материалов, проведение социологических опросов, фокус-групп, "кругльх столов", подготовка аналитических записок и т.п.).

создание научно-методического сопровождения экспертной работы.

4. Содействие формированию и развитию компетенций по ОРВ у студенческой молодежи:

разработка и внедрение в образовательный процесс программ спецкурсов (модулей), факультативов в рамках реамизации образовательных программ высшего образования;

организация практики и выездных занятий в органах исполнительной вцасти и их структурньх подраздемениях, уполномоченных по проблемам ОРВ;

формирование тематики курсовых и выпускных квалификационных работ обучающихся по проблемам OPB;

организация региональных и межрегиональньгх конкурсов, олимпиад дия молодежи по вопросам регуляторной помитики в ДФО.

В резумьтате консолидации усилий участников механизма ОРВ путем создания межрегионального центра компетенций будут созданы условия для формирования единого научно-образовательного пространства в области регуляторной помитики на территории Дальневосточного 
федерального округа, что в свою очередь, будет способствовать развитию кадрового обеспечения ОРВ.

\section{Список литературы:}

1. Информаиионный портал об Оиенке Рeгулирующего Воздействия. URL: //orv.gov.ru.

2. Поливаева О.Г. Роль образовательных организаций в оценке регулируюшего воздействия проектов и экспертизы действуюиих нормативных правовых актов // Экономика. управление, обиество: история и современность: материалы XIV Всероссийской научнопрактической конференции. Хабаровск: Даль- невосточный институт управления - филиала PAHXUГC. 2016. C. 259-262.

\section{References:}

1. Informacionnyj portal ob Ocenke Reguliruyushchego Vozdejstviya. URL: //orv.gov.ru. 2. PolivaevaO.G. Rol'obrazovatel'nyhorganizacij v ocenke reguliruyushchego vozdejstviya proektov $i$ ehkspertizy dejstouyushchih normativnyh pravovyh aktov // EHkonomika. upravlenie, obshchestvo: istoriya i sovremennost': materialy XIV Vserossijskoj nauchno-prakticheskoj konferencii. Habarovsk: Dal'nevostochnyj institut upravleniyafiliala RANHiGS. 2016. S. $259-262$. 